\title{
A part of but apart from politics
}

Can scientists advise policy-makers without compromising their objectivity?

\section{Nature's Experts: Science, Politics, and the Environment by Stephen Bocking Rutgers University Press: 2004. 304 pp. $\$ 60, £ 44.50(h b k) ; \$ 24.95, £ 17.50(p b k)$}

\section{Roger Pielke Jr}

In this excellent book on environmental science and politics, Stephen Bocking grapples with a problem that he characterizes as a riddle: "How can science be part of the political process yet separate?" Or more specifically: "How can we ensure that scientific research provides the information we need to pursue our environmental values and priorities (whether these relate to exploitation or to protection) without science itself becoming subject to the conflicts and controversies of environmental politics?"

For decades, the riddle posed by Bocking was answered through a widely shared conceptual model about the role of science in society, presented most influentially in Vannevar Bush's 1945 report to government, Science: The Endless Frontier. The policy advocated by Bush depended on a distinction between basic and applied research, with basic research contributing to a reservoir of knowledge that could be tapped to solve problems and exploit opportunities. Basic research was characterized simply as the quest for knowledge; it was pure. The elegance of the plan is that basic research was also fundamental to societal progress, and hence was part of the political process. Science was both separate from, and yet a part of, politics and decision making. This blueprint created momentum that was ultimately expressed in the creation of the US National Science Foundation. But the Bush report is remembered chiefly for its expression of the axiology and culture of science - it proposed that science should be led by scientists, not politicians - rather than for its ideas for creating institutions.

Bush's science policy has always had its critics, but only in the past decade or so have their criticisms been accompanied by shifts in science policy. Scholars of science and politics have begun to characterize conceptual models for science policy that move away from his model. An example is provided by Helga Nowotny, chairwoman of the European Research Advisory Board of the European Commission, and her colleagues. She says the old paradigm of scientific discovery "characterized by the hegemony of disciplinary science, with its strong sense of an internal hierarchy between the disciplines and driven by the autonomy of scientists and their host institutions, the universities" is

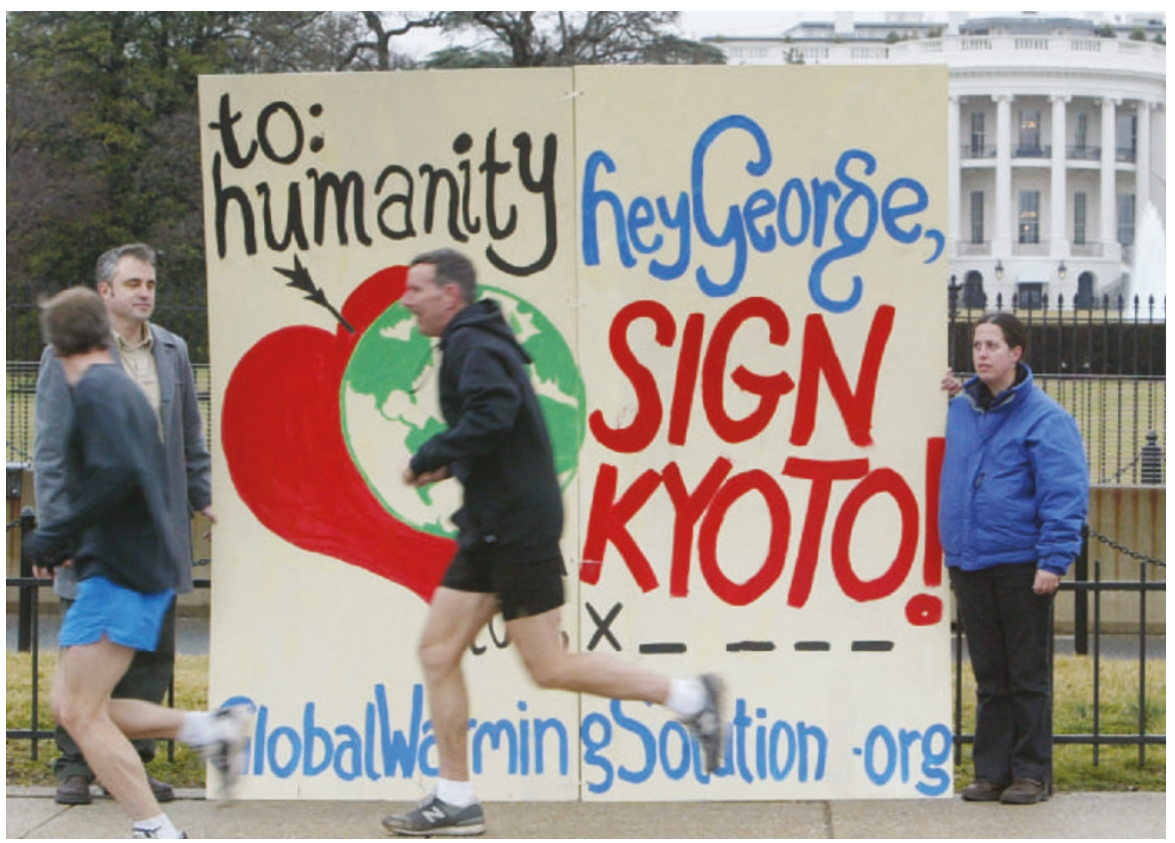

Valentine's message: passions can run high when scientists get involved in the political process.

being superseded, but not replaced, by a new paradigm of knowledge production. The new paradigm is "socially distributed, application-oriented, trans-disciplinary and subject to multiple accountabilities".

Another characterization of the move away from the old Bush model is the late Princeton historian Donald Stokes's 1997 model Pasteur's Quadrant, which reflects "use-inspired basic research" — a concept that is oxymoronic in the context of the Bush model. This sort of thinking has led, for example, to the adoption of the National Science Foundation's second review criterion, which focuses the evaluation of research proposals on societal impacts of research, and to ever more attention to scientific assessments and advisory bodies as important institutions in the policy process.

Scholars of science, technology and society have developed a robust body of knowledge that shows the flaws in the Bush science policy, and some parts of the community have experimented with alternatives. Even so, the Bush model is still widely embraced by many scientists and policy-makers. For instance, in 2004 the US National Research Council issued a report on scientific advisory committees, recommending that political considerations should not play a role in the process of deciding whom to appoint to policy panels. Yet its own membership, drawn from former government officials appointed by past presidents, reflected a perfect political balance of those appointed by Republicans and those appointed by
Democrats. Similarly, the Intergovernmental Panel on Climate Change has the temerity to claim that it is "policy neutral", yet its website trumpets its success in advocating the adoption of the Kyoto Protocol to the Framework Convention on Climate Change. As science policy has changed, these actions show signs of schizoid behaviour - the result of efforts to keep science both part of and separate from politics at a time of fundamental change in science policy.

In the context of this change in the role of science in society, Bocking clearly explains that the authority of science is ephemeral. He quotes Dorothy Nelkin: "As scientists debate the various sides of politicized issues, their involvement undermines assumptions about the objectivity of science, and these are precisely the assumptions that have given experts their power as the neutral arbiter of truth." By participating in political debates as advocates for special interests, scientists are reducing their claim to authority. Science becomes "politics by other means".

Two accessible chapters provide an overview of literature from the fields of science and technology studies, and policy. They cogently present many of the complexities and contradictions of science in policy and politics. Bocking presents well-informed discussions of three cases: natural resources management, global environmental change, and chemicals in the environment. Each chapter is well written and argued but is chock full of detail and allusion that may make them most meaningful to those 
